Ian David Lockhart Bogle and Michael Fairweather (Editors), Proceedings of the 22nd European Symposium on Computer Aided Process Engineering, 17 - 20 June 2012, London.

(C) 2011 Elsevier B.V. All rights reserved.

\title{
Environomic optimal design and synthesis of energy conversion systems in urban areas
}

\author{
Léda Gerber, Samira Fazlollahi, François Maréchal \\ Industrial Energy Systems Laboratory (LENI), Ecole Polytechnique Fédérale de Lau- \\ sanne, CH-1015 Lausanne, Switzerland, leda.gerber@epfl.ch
}

\begin{abstract}
The integration of environmental impacts in the conceptual design of energy systems can be achieved by combining Life Cycle Assessment (LCA) with process integration techniques. The use and the disaggregation of life cycle inventory (LCI) databases allows for extending the systematic generation of resources to services conversion chains and for including the environmental impacts in the process design procedure. This paper presents how to systematically generate the superstructure of the energy conversion system, how to solve the urban energy system design using a multi-period multi-objective optimization and how the environmental objectives can be integrated in the process design procedure.
\end{abstract}

Keywords: process design, process synthesis, optimization, energy systems, life cycle assessment, industrial ecology, urban systems

\section{Introduction}

The industrial ecology aims at identifying in a given system the possible exchanges that allow to mitigate the use of resources and the environmental impacts of industrial activities. The design of an industrial symbiosis can be solved by extending the process design techniques to larger systems including not only the process flowsheet design but also the choice of the raw materials, the supply chains and the waste management and recycling options. In parallel, the integration of environmental impacts in the conceptual process design procedure has gained considerable interest in the last decade, and several studies deal with the integration of environmental impacts in the process design procedure and optimization (Guillén-Gosálbez et al. (2008); Hugo and Pistikopoulos (2005); Gerber et al. (2011a)). One of the ways of achieving this is to combine Life Cycle Assessment (LCA) tools with flowsheeting software and process integration techniques, which allows for directly linking the Life Cycle Inventory (LCI) with the process design decisions such as the configuration, scale and operating conditions (Gerber et al. (2011a)).

An application of this methodology concerns the design of urban energy systems with several endogenous potential resources, multiple energy services to be supplied and waste generated to be treated, in a context submitted to seasonal variations. This paper presents an extension of the methodologies for LCA integration in process systems design using a LCI database (Gerber et al. (2011a,b)) for urban energy conversion systems. It includes the systematic generation of the superstructure of potential technologies and resources, and the formulation of the optimization problem to integrate environomic (economic and environmental) aspects in the selection of optimal configurations. A case study is as well presented to illustrate the application of the methodology.

\section{Methodology}

To design the system, a computational framework is used for the simulation, the design and the optimization of energy systems accounting for multi-period aspects (Fazlollahi 
Ian David Lockhart Bogle and Michael Fairweather (Editors), Proceedings of the 22nd European Symposium on Computer Aided Process Engineering, 17 - 20 June 2012, London.

(C) 2011 Elsevier B.V. All rights reserved.

and Maréchal (2011)), presented in Figure 1. The optimization problem, aiming at mini-

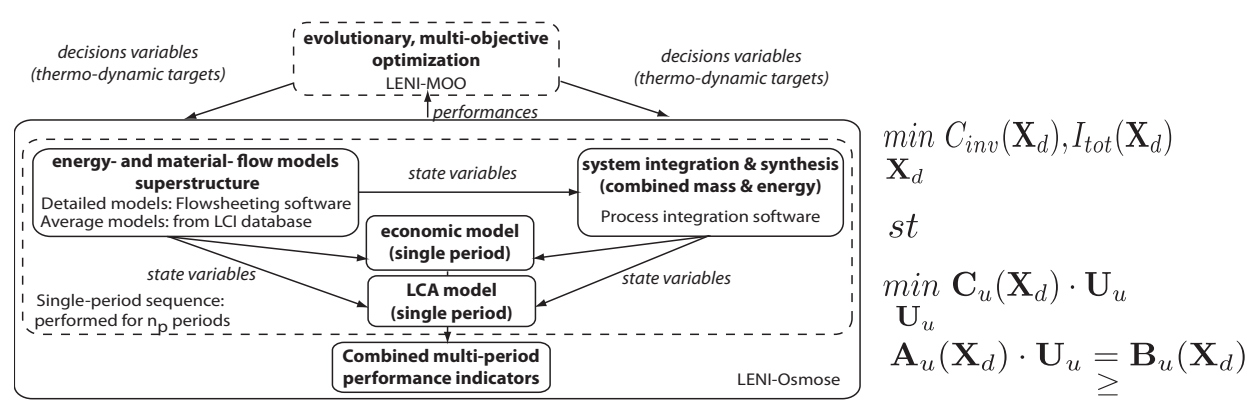

Figure 1: Computational framework used for system design and optimization

mizing simultaneously the costs and the impacts is by essence a Mixed Integer Non-Linear Programming (MINLP) multi-objective optimization problem. It is solved following a two stage decomposition methodology with a master problem and a slave sub-problem. The slave optimization sub-problem concerns the combined mass and energy integration of the system, aiming at minimizing the system operating costs including the environmental taxes. It is solved as a Mixed Integer Linear Programming (MILP) problem. The master problem, subject to the slave sub-problem, deals with the process unit sizing variables and is solved as a multi-objective optimization of the non-linear investment costs and impacts of the system.

A LCI database is used to account for the off-site emissions due to the auxiliary materials, the waste handling and the logistics included in the LCA system boundaries. The decision perimeter of the system has to be extended beyond the flowsheet design to account for the decisions that can be taken on the average technologies, on the waste management and recycling options, and on the supply chains. LCI data from the ecoinvent database (Frischknecht et al. (2005)) can be disaggregated in units with associated impacts and material flows. Then, a superstructure based process design methodology can be applied (Gerber et al. (2011b)). The superstructure of the system to be designed is decomposed in three different types of sub-components: 1) the technologies on which actions can be undertaken and that are modeled in details, 2) the average technologies of the LCI database, and 3) the resources imported in the system, taken from the LCI database. Each one of the units having associated material and energy flows, the synthesis of the system using process integration techniques allows for the systematic generation of mass and heat exchanges opportunities in the system.

The superstructure used as a basis for the synthesis of an urban energy system contains thus five different subsystems: 1) the available resources (endogenous and imported), 2) the conversion technologies to convert resources into final energy services or intermediate products, 3) the services to be supplied, 4) the waste to be treated and 5) the transfer networks. Each unit contained in these subsystems has associated mass and energy flows, operating $\left(\mathrm{CO}_{u}\right)$ and investment costs $\left(\mathrm{CI}_{u}\right)$, and environmental impacts $\left(\mathrm{I}_{u}\right)$ calculated with the disaggregated data of the LCI database, all calculated for a nominal size $\left(f_{u}=1\right)$. It has as well a minimal and maximal sizing factor $\left(f_{\min }\right.$ and $\left.f_{\max }\right)$, which depends on if the unit is a process $\left(f_{u}=1\right)$, a utility with unlimited use $\left(f_{\max }=\right.$ unlimited $)$ or with limited use $\left(f_{\max }=\right.$ limited $)$. The example of such a superstructure is showed in Figure 2.

Then, the system is synthesized for each period in order to account for the seasonal variations of the demand in energy services and in the resource availability. A MILP formulation is used to optimize the utilization factors of each unit of the superstructure, minimizing the operating costs including the environmental tax due to the on-site and 
Ian David Lockhart Bogle and Michael Fairweather (Editors), Proceedings of the 22nd European Symposium on Computer Aided Process Engineering, 17 - 20 June 2012, London.

(C) 2011 Elsevier B.V. All rights reserved.

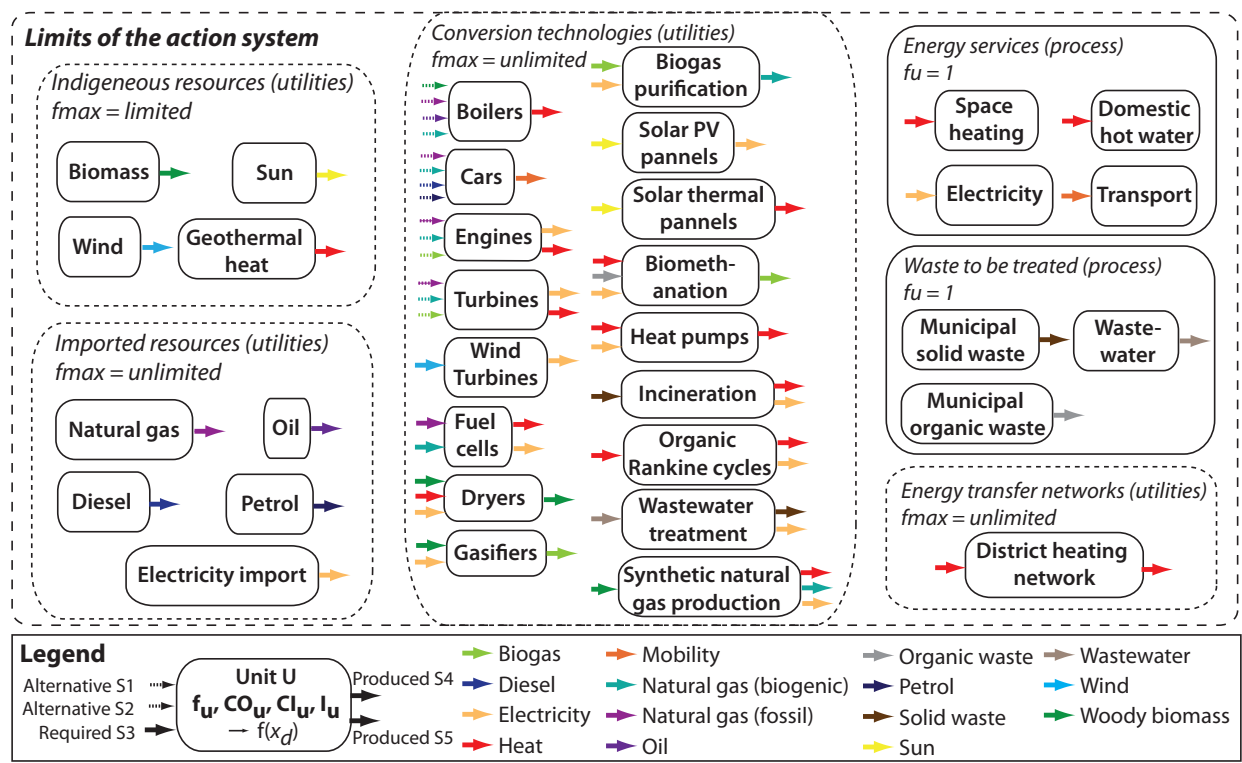

Figure 2: Example of a superstructure for urban energy systems synthesis

off-site $\mathrm{CO} 2$ emissions:

$$
\min \left(C_{O, p}=\sum_{u=1}^{n_{u}} \mathbf{f}_{\mathbf{u}, \mathbf{p}} \cdot\left(C_{O, u, p}+E_{C O 2, u, p} \cdot \mathrm{c}_{\mathrm{co} 2}+\dot{E}_{u, p}^{+} \cdot c_{e^{+}}+\dot{E}_{u, p}^{-} \cdot c_{e^{-}}\right)\left(\mathrm{x}_{\mathrm{d}}\right)\right)
$$

where $\mathbf{f}_{\mathbf{u}, \mathbf{p}}$ is the utilization factor of utility $u$ during period $p, C_{O, u, p}$ its operating cost, $E_{C O 2, u, p}$ its equivalent $\mathrm{CO}_{2}$ emissions, $\mathrm{c}_{\mathrm{co} 2}$ the environmental tax, which can be given as a decision variable of the master problem, $\dot{E}_{u, p}^{+}$is its electricity consumed, $\dot{E}_{u, p}^{-}$is its electricity produced, $c_{e^{+}}$is the specific cost of the electricity from the grid and $c_{e^{-}}$of electricity sold to the grid. $\mathbf{f}_{\mathbf{u}, \mathbf{p}}$ represent the decision variables of the MILP slave subproblem, and $\mathrm{x}_{\mathrm{d}}$ the ones of the master problem. This is submitted to the constraints of the heat cascade with heat exchange restrictions (Becker and Maréchal (2011)), necessary since the heat demand is satisfied via the district heating network, and to the constraints of mass balance in the mass exchange superstructure (Gerber et al. (2011b)).

Once the system has been synthesized for each period, the final investment costs and life-cycle environmental impacts are calculated accounting for the scheduled yearly operation. They are then used as objective functions of the non-linear multi-objective optimization problem:

$$
\min \left(C_{t o t}=\sum_{u=1}^{n_{u}} \max \left(C_{i n v, u, p}\left(\mathbf{x}_{\mathrm{d}}, \mathbf{f}_{\mathbf{u}, \mathbf{p}}\right)\right)\right)
$$

where $C_{i n v, u, p}$ is the investment cost of utility $u$ associated with period $p$, the maximum value representing the investment to be realized. The second objective function concerns the total environmental impacts calculated by life cycle impact assessment:

$$
\min \left(I_{t o t}=\sum_{u=1}^{n_{u}}\left(\max \left(I_{C, u, p}\right)+\max \left(I_{E, u, p}\right)+t_{p} \cdot \sum_{p=1}^{n_{p}} I_{O, u, p}\right)\left(\mathrm{x}_{\mathrm{d}}, \mathrm{c}_{\mathrm{co} 2}, \mathbf{f}_{\mathbf{u}, \mathbf{p}}\right)\right)
$$

where $I_{C, u, p}$ is the impact associated with the construction of utility $u$ for period $p, I_{E, u, p}$ with its end-of-life (i.e. dismantling and disposal), and $I_{O, u}$ with its operation, including 
Ian David Lockhart Bogle and Michael Fairweather (Editors), Proceedings of the 22nd European Symposium on Computer Aided Process Engineering, 17 - 20 June 2012, London.

(C) 2011 Elsevier B.V. All rights reserved.

both the auxiliary materials and emissions. The impacts due to construction and end-oflife can be assimilated to an environmental investment. Thus, their value within the multiperiod framework is calculated by analogy with the investment, by taking the maximal value among the ones calculated for each period.

\section{Case study}

The methodology is applied to the design and synthesis of an urban energy system for a city of 40'000 inhabitants in Switzerland, for which the seasonal quantities of energy services, waste and availability of endogeneous resources have been characterized. The superstructure of Figure 2 is considered. In order to satisfy the decomposition conditions and make the sub-problem compatible with the objective of the master problem, the $\mathrm{CO} 2$ tax is considered as a master problem decision variable. An evolutionary non-dominated algorithm (Molyneaux et al. (2010)) is used for multi-objective optimization, considering the minimization of the investment costs and of the life cycle equivalent emissions of carbon dioxide evaluated with the impact assessment method of the single score of the impact assessment method ecoindicator99-(h,a) (Goedkoop and Spriensma (2000)). The environmental objective is chosen to have a more global appreciation of the performance than just the equivalence of $\mathrm{CO} 2$ emissions, and includes as well effects on the human health, on the ecosystem quality and on the non-renewable resources.

\section{Results}

Results from the multi-objective optimization for the case study are displayed in Figure 3. Minimum and maximum $\mathrm{CO} 2$ emissions are correlated with the total environmental

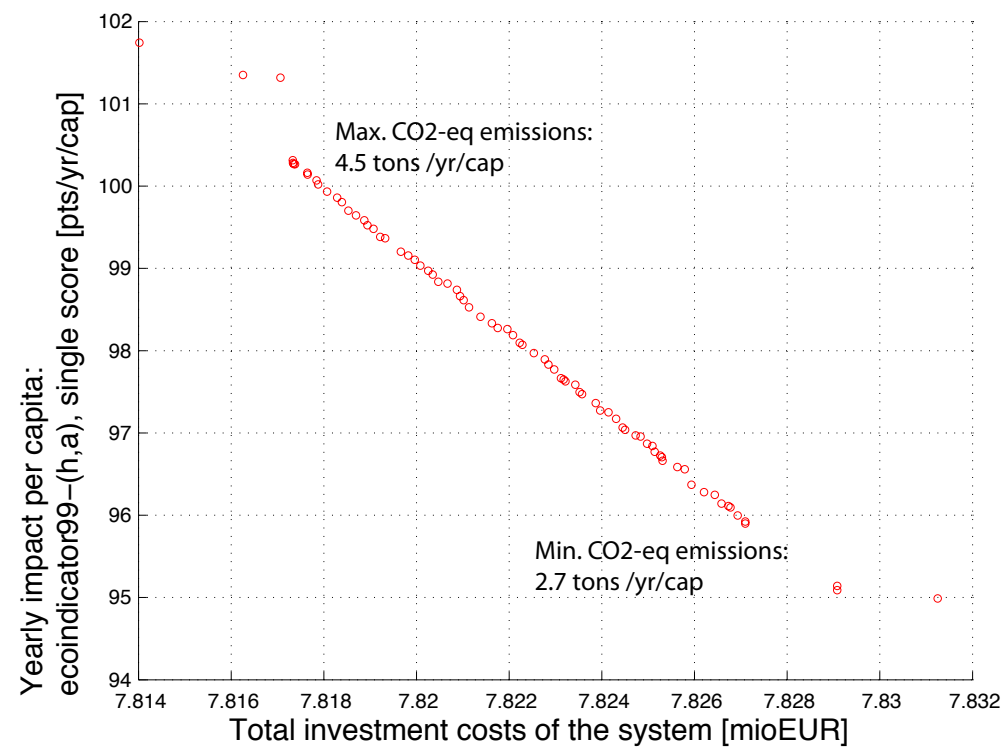

Figure 3: Trade-off between investment costs and impacts for synthesis of urban system taken as a case study

impacts of the system. The limits for the CO2 tax were given between 0 and $200 \mathrm{EUR} / \mathrm{kg}$ in the optimization, but the optimal configuration all have a tax comprised between 10 
Ian David Lockhart Bogle and Michael Fairweather (Editors), Proceedings of the 22nd European Symposium on Computer Aided Process Engineering, 17 - 20 June 2012, London.

(C) 2011 Elsevier B.V. All rights reserved.

and $90 \mathrm{EUR} / \mathrm{kg}$. Indeed, beyond $90 \mathrm{EUR} / \mathrm{kg}$, the tax does not allow to reduce the impacts anymore. On the other hand, a tax inferior to $10 \mathrm{EUR} / \mathrm{kg}$ does not penalize the investment.

\section{Conclusions}

A systematic methodology for the environomic optimal design of urban energy systems has been presented. It combines the principles of process design and integration, life cycle assessment and industrial ecology, and accounts simultaneously for the potential conversion technologies, supply chains, logistics and recycling possibilities. It can be applied to provide some help in the decision-making procedures and in territorial planning. A practical example is the determination of the optimal value of a $\mathrm{CO} 2$ tax to mitigate the environmental impacts from energy services supply and waste treatment, and the identification of the optimal conversion chains for endogenous resources such as biomass or biowaste processing.

\section{References}

Becker, H. and Maréchal, F. 2011. Energy integration of industrial sites with heat exchange restrictions. Computers \& Chemical Engineering, page doi:10.1016/j.compchemeng.2011.09.014.

Fazlollahi, S. and Maréchal, F. 2011. Multi-Objective, Multi-Period Optimization of Biomass Conversion Technologies Using Evolutionary Algorithms and Mixed Integer Linear Programming (MILP). Applied Thermal Engineering, page doi:10.1016/j.applthermaleng.2011.11.035.

Frischknecht, R., Jungbluth, N., Althaus, H.-J., Doka, G., Dones, R., Heck, T., Hellweg, S., Hischier, R., Nemecek, T., Rebitzer, G., and Spielmann, M. 2005. The ecoinvent database: Overview and methodological framework. International Journal of Life Cycle Assessment, 10:3-9.

Gerber, L., Gassner, M., and Maréchal, F. 2011a. Systematic Integration of LCA in process systems design: Application to combined fuel and electricity production from lignocellulosic biomass. Computers \& Chemical Engineering, 35:1265-1280.

Gerber, L., Mayer, J., and Maréchal, F. 2011b. A systematic methodology for the synthesis of unit process chains using Life Cycle Assessment and Industrial Ecology Principles. Computer Aided Chemical Engineering, 29:1215-1219.

Goedkoop, M. and Spriensma, R. 2000. The Eco-Indicator 99: A damage oriented method for life cycle impact assessment. Technical report, PRé Consultants, Amersfoort, The Netherlands.

Guillén-Gosálbez, G., Caballero, J., and Jiménez, L. 2008. Application of Life Cycle Assessment to the Structural Optimization of Process Flowsheets. Industrial and Engineering Chemistry Research, 47:777-789.

Hugo, A. and Pistikopoulos, E. 2005. Environmentally conscious long-range planning and design of supply chain networks. Journal of Cleaner Production, 13:1471-1491.

Molyneaux, A., Leyland, G., and Favrat, D. 2010. Environomic multi-objective optimisation of a district heating network considering centralized and decentralized heat pumps. Energy, 35:751-758. 